\title{
L'epistolari de Rossend Serra Pagès: les folkloristes catalanes de començaments del segle $\mathrm{xx}$
}

\author{
Montserrat Palau Vergés \\ Universitat Rovira i Virgili \\ montserrat.palau@urv.cat
}

\begin{abstract}
RESUM
L'anàlisi de l'epistolari que Rossend Serra Pagès va mantenir amb algunes de les seves alumnes de les classes de Folklore a l'Escola d'Institutrius i Altres Carreres per a la Dona ens permet constatar també des d'aquesta disciplina que les dones de principis del segle $x x$ que van prendre part de forma activa en la vida cultural catalana pertanyien a unes classes benestants i que, des d'un ordre social conservador i seguint les premisses d'un feminisme burgès, ho van fer sense subvertir els papers assignats. Tot i això, sí que van modificar alguns dels codis socials que limitaven les vides de les dones, obrint nous espais de llibertat. I, tenint en compte les seves aportacions, van contribuir a l'estudi del folklore i a la promoció dels drets de les dones en els àmbits educatius, culturals i laborals.
\end{abstract}

PARAULES CLAU

història del folklore; literatura catalana; estudis de dones; epistolari; Rossend Serra Pagès

\section{ABSTRACT}

The correspondence between Rossend Serra Pagès and some of his students who attended his classes on folklore at the School for Governesses and other professions for women, shows some interesting evidence: the women at the beginning of the 2oth century who took an active part in Catalan culture came from the well-to-do classes. Moreover, as they belonged to a social order which was conservative and followed the principles of bourgeois feminism, these women managed to be active without subverting the established roles. They did modify some of the social codes, however, especially those that limited their lives. Thus, they opened doors to new spaces of freedom and contributed towards the study of folklore and the promotion of women's rights within education, culture and employment.

\section{KEYWORDS}

history of folklore; catalan literature; women studies; collected letters; Rossend Serra Pagès 
Si DURANT EL SEGLE XIX les ideologies de caire liberal ja van apostar per l'educació i capacitat intel-lectual femenines, en el canvi cap al segle XX, en diversos països d'Europa i de l'Amèrica del Nord, s'imposa un nou model per a les dones, fins aleshores recloses a l'àmbit domèstic, el de la new woman, la dona moderna, amb accés a la formació i al món laboral i amb més llibertat vital. ${ }^{\mathrm{I}}$ A diferència d'altres nacions, però, a Catalunya triomfaran els postulats d'un feminisme burgès, més conservador, que, en contraposició als aires de secularització i emancipació promoguts per moviments sufragistes internacionals, advocà per un model més tradicional. Aquest feminisme, tanmateix, fou un agent educador i dinamitzador de la cultura femenina i va permetre, tot creant escoles i institucions, l'accés de les dones al món cultural i, en concret, als estudis de folklore. En uns moments de construcció nacional, el poder polític també tenia clar el paper de les dones com a transmissores de cultura, tradicions i identitat i, en aquest sentit, l'estudi del folklore era una tasca del tot adient i femenina (Palau 2OI2: I3-I6). Són dones de classes mitjanes i benestants, que reben una formació específica, que els és ocupació però també distracció mentre són solteres o es preparen per a una professió, tot i que unes quantes continuaran conreant-lo posteriorment, com és el cas d'algunes de les deixebles de Rossend Serra Pagès.

Un dels factors clau de l'aparició d'un ampli grup de dones estudioses del folklore a Catalunya a principis del segle $\mathrm{xx}$, segons han constatat les recerques que en els darrers anys s'han interessat per aquest tema, ${ }^{2}$ són les classes que el professor Rossend Serra Pagès (I863-I929) va impartir, entre I9OI ${ }^{3}$ i I9I7, a l'Escola d'Institutrius i Altres Carreres per a la Dona, a Barcelona. ${ }^{4}$ El seu mestratge va anar més enllà de les aules i algunes de les seves deixebles es van dedicar amb entusiasme a la recol-lecció de material i van fer aportacions importants en aquest camp. Rossend

\footnotetext{
I. Aquest article forma part de la investigació del Grup de Recerca Identitats en la Literatura Catalana (GRILC) (20I4 SGR 755) del Departament de Filologia Catalana de la Universitat Rovira i Virgili, i s'emmarca en una línia de recerca sobre literatura popular catalana que ha rebut finançament del Ministeri d'Economia i Competitivitat a través del projecte d'R+D FFI2OI2-31808.

2. Cal esmentar sobretot els treballs, tant de caire generalista com monogràfics sobre folkloristes en concret, de Curbert (2007), Grau (1999a i I999b), Llopart i Ros (2012), Oriol (2010 i 20I2), Palau (20I2), Pujadas (2004a i 2004b), Roma i Marin (I996), Roma (2006, 20II i 20I2), Soler Amigó (2OIO) i Villalba (20I2 i 20I3).

3. El mateix any, el I9or, en què el Centre Excursionista de Catalunya permet «l'ingrés de dames i senyoretes» i que es crea la secció de Folklore dirigida per Rossend Serra Pagès (Butlletí del Centre Excursionista de Catalunya núm. 243 [abril I9I5]: IIO). <http://ddd.uab.cat/pub/ butcenexccat/butcenexccat_aI9I5m4v25n243.pdf> [Data de consulta: novembre 20I3].

4. I, des del I9I7, un cop tancada l'escola, a casa de la professora Agnès Vandrey (Serra i Boldú I935: 827).
} 
Serra Pagès va formar a l'Escola d'Institutrius un grup de noies que «l'admiraven i seguien bocabadades les seves instruccions» (Llopart-Ros 20I2: 45). Per al professor, aquesta docència també fou una inversió perquè, així, va poder disposar d'un estol d'informants que es movien per diferents punts geogràfics i que podien accedir més fàcilment a les entrevistes amb altres dones i amb la mainada (Roma I996: 80). ${ }^{5} \mathrm{Al}$ mateix temps, quan li demanaven treballs folklòrics per publicar, els enviava els de les seves deixebles «desitjant que no es quedin inèdits» i, malgrat la poca presència que van tenir en les revistes de l'època, van realitzar una tasca «gens menyspreable ni en quantitat ni, sobretot, en qualitat» (Villalba 20I3: 99-IOI).

Rossend Serra Pagès, descrit com a home de «fort temperament i engrescador en la feina» (Juan 20II: 55), fou un seductor, amb capacitat, seguint l'etimologia del terme, de persuadir i atraure un conjunt de dones perquè s'interessessin pel folklore. No tan sols un bon nombre d'alumnes li va retre homenatge i li va dedicar un llibre (Alguns escrits del professor Rossend Serra y Pagès, coleccionats y publicats a honor del Mestre per les seves deixebles en ocasió del Cinquantenari del seu Professorat, I926), ${ }^{6}$ sinó que, fins i tot, unes quantes, el dia del seu funeral, el I930, van organitzar al seu estudi un acte íntim de comiat (Massot i Muntaner 20IO: I47).

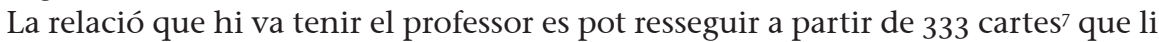
van enviar 22 alumnes seves de l'Escola (annex final amb els noms, nombre de cartes i dates).

El conjunt de cartes és ben diferent, tant de quantitat com de contingut. El folklore, però, sigui pel reconeixement que li fan com a mestre o per l'intercanvi d'informacions i materials, hi és gairebé sempre present. Hi ha un primer bloc més circumstancial amb poques cartes o postals creuades amb alumnes que estan d'estiueig, o de viatge o que han acabat els estudis recentment: Emília Estartús Prats, Manuela Fina Vergés, Antonieta Orriols, Rosa Pagès Bataller, Teresa i Emília Torras, Carmen Fernández, Consol i Rosa Planas Regordosa, Mercè i Magdalena Torres. Un altre bloc, tampoc no gaire nombrós, són les cartes creuades amb alumnes que o eren col-legues de feina quan Rossend Serra Pagès impartia docència a l'Escola, com Josepa Brichs Quintana, ${ }^{8}$ o que, amb el temps, ho seran en el món de

5. Aquest poder per accedir a la informació el resumeix molt clarament una frase que escriu Sara Llorens al mestre a l'inici de les seves recerques folklòriques: «La gent senzilla és tota meva» (I8 de juny del I904).

6. També en el fons personal dipositat a l'Arxiu de Barcelona, es conserva un document de I87 fulls, «Record de l'Homenatge al Professor En Rossend Serra i Pagès». És un llibre de signatures, precedit d'una ressenya explicativa del procés i l'organització de l'homenatge, signada per Maria Oller i datada l'I de març del I928, que inclou dibuixos, fotografies partitures musicals i cartes des del I9I9 fins al I927. <http://wiro.bcn.cat/ArxiuHistoric/Continguts/ Documents/Fitxers/Serra\%2oPag\%C3\%A8s, \%20Rossend\%2O\%281a\%2opart\%29\%20 \%285D.61\%29.pdf> [Data de consulta: novembre 20I3].

7. No tenim en compte una carta curta d'admiració i agraïment de Sara Llorens i Joana Parcerisa acabat el seu primer curs amb el professor (26 de juny del I90I) i una notificació conjunta. Cal tenir present també que, gairebé la meitat, I27, són cartes d'una sola remitent, Sara Llorens. Amb problemes de salut crònics, des de Pineda de Mar i altres indrets (Argentina, Canàries...), Sara Llorens, ja en la primera carta que va dirigir a Rossend Serra Pagès, expressava un desig que esdevindria realitat: «el folklore serà el meu acompanyant tota la vida» (I8 de juny del I904).

8. Josepa Brichs es va titular amb qualificació d'excel-lent (La Vanguardia, I8 de juny del I898), a l'Escola d'Institutrius, on hi va entrar a treballar com a mestra de diverses matèries 
la cultura catalana, com Maria Oller Rabassa o Narcisa Freixas Cruells. ${ }^{9}$ Un tercer apartat, de forma circumstancial però intensa en els anys en què es va produir, és la correspondència mantinguda amb les alumnes Antònia Quinquer Golobart i Anna Queraltó Latorre, sobre temes més personals amb la primera i sobre folklore i altres qüestions amb la segona. També en aquest apartat, caldria incloure les cartes que, més espaiades en el temps, va mantenir amb l'antiga deixebla Maria Vivó, que s'havia traslladat a Montevideo. I, finalment, el grup més important en nombre de cartes i d'una relació que va continuant al llarg dels anys, és el de les deixebles que van seguir la tasca d'estudi del folklore o d'altres activitats culturals, amb més o menys dedicació, com Sara Llorens Carreras, Adelaida Ferrer Gomis, Maria Baldó Massanet, Joana Vidal Tarragó, Maria Gràcia Bassa Rocas i Mercè Ventosa Clavell.

Un cop analitzada aquesta correspondència epistolar que va mantenir amb aquestes alumnes i que es conserva al fons que porta el seu nom a l'Arxiu Històric de la Ciutat de Barcelona, podem ratificar aquesta afirmació: Rossend Serra Pagès fou un mestre convincent i, alhora, càlid i comprensiu fins a esdevenir conseller i amic. Aquest conjunt de cartes, ben diferent en quantitat i contingut segons les emissores, ens permet disposar de més dades que ajuden a establir les biografies i tipologies d'aquestes folkloristes, alhora que, contrastat amb altres recerques, ens aporten més documentació i matisos per contextualitzar-ne l'aparició i el treball que van dur a terme.

Aquestes folkloristes eren alumnes de l'Escola d'Institutrius, una institució de prestigi. Creada el I87o per la Societat Econòmica Barcelonesa d'Amics del País, era una fórmula substitutòria, per a les dones d'unes classes socials determinades, dels estudis universitaris, aleshores masculinitzats. ${ }^{\text {Io }}$ Seguint els nous cànons internacionals, la burgesia catalana també va començar a educar les seves filles, però dins d'uns paràmetres que les excloïa de l'educació que rebien els homes. La burgesia catalana va apostar també per fomentar l'accés de les dones a la formació i a algunes esferes de treball, però, a diferència d'altres moviments europeus del mateix caire en aquelles dècades, des de posicions catòliques i conservadores. Així, tal com es desprèn de les línies de govern del partit de la Lliga Regionalista al capdavant de les institucions, com de les teories del feminisme burgès que en va sorgir, més cultural que no polític, les funcions bàsiques de les dones estaven encara només definides pel seu sexe i naturalesa. L'accés de les dones a l'educació també superior servia a la burgesia o bé per preparar-les com a esposes i mares, perpetuadores dels valors i la identitat, o bé, en uns moments de crisi econòmica, en què creixia el nombre de solteres i minvava la possibilitat de les dots, sortir del rol de «tieta», com deia Maria Aurèlia Capmany, i dedicar-se a unes ocupacions determinades (Capmany I973: I2-

(Aritmètica, Geometria, Història d'Espanya...). I assistia d'alumna a les classes de Rossend Serra Pagès i va participar en els diversos actes i homenatges que se li van retre.

9. A excepció d'una nota enviada el I9II, la resta de cartes de Maria Oller són demandes d'informacions acadèmiques i històriques a Rossend Serra Pagès per a la seva feina de pintora. I Narcisa Freixas envia 4 cartes com a directora de la Biblioteca Juvenil de Cultura Musical Popular al «distingit amic» $\mathrm{i}$ «consoci» referents a diversos actes sobre folklore que organitza aquesta entitat i en què vol que el mestre participi.

Io. Cal tenir en compte que Maria Helena Maseras, la primera universitària, no va aconseguir una autorització del rei espanyol per ingressar a la Facultat de Medicina de la Universitat de Barcelona fins al 1872 . 
I8). El feminisme català burgès fou un agent educador i dinamitzador de la cultura femenina com a instrument d'emancipació de les dones. Així, les revistes d'aquests sectors polítics i intel-lectuals es feien també ressò dels estudis de folklore com a mostra d'aquesta cultura i emancipació femenines. ${ }^{\text {II }}$

El mateix Rossend Serra Pagès, el I904, en la conferència «Un planter d'escriptores catalanes», impartida al Centre Excursionista de Catalunya, es dolia de l'«endarreriment intel-lectual» de les dones catalanes i es felicitava pels esforços d'haver creat l'Escola d'Institutrius i Altres Carreres per a la Dona, que, però, «ben poc ha correspost el públic» i que, malgrat les poques deixebles que ha tingut, «n'han sortit vàries que són una esperança per a les lletres catalanes» (Butlletí del Centre Excursionista de Catalunya, any XIV, abril del I904). ${ }^{12}$ Seran algunes d'aquestes alumnes dels primers anys les que més destacaran, tant en el camp del folklore com en altres tasques culturals i intel-lectuals i, al mateix temps, algunes de les integrants d'aquest primer grup seran les que mantindran amb el mestre una correspondència més fluïda $\mathrm{i},{ }^{\mathrm{I}}$ alhora, una relació personal més intensa. ${ }^{14}$

Les cartes, en la majoria dels casos, s'inicien en el moment del mestratge a les classes i, amb unes quantes, sigui per continuïtat de la col-laboració en tasques culturals i de tasques de recerca folklòrica o, simplement, de l'apreciació i l'amistat, continuen fins gairebé el final de la vida del professor. En els anys d'estudiants es repeteixen, amb poques variacions, les mateixes fórmules d'encapçalament i comiat: «Benvolgut mestre» i «La seva afectíssima deixebla». I gairebé sempre hi trobem salutacions de part dels «papàs» o la família, que tenen coneixença i tutelen tant les activitats escolars i folklòriques com la correspondència que mantenen les seves filles. Així, per exemple, Emília Estartús Prats agraeix al professor la revista que li ha enviat que conté un article que els havia llegit a classe, perquè, gràcies a la publicació, «els pares han comprès la importància de l'estudi del folk-

II. La revista Or i Grana, setmanari «autonomista per a dones catalanes» —d'un feminisme molt conservador-, basat en idearis de Solidaritat Catalana i de la qual Narcisa Freixas formava part del consell editorial, en el número 2 (I3 d'octubre del I906) publica l'article «Es critica que les mares canten sarsueles als nens i no cançons catalanes tradicionals». La revista també es fa ressò tant de les sessions de folklore que se celebren al Centre Excursionista de Catalunya com d'altres tasques i publicacions d'aquestes autores. Així, el 24 de novembre del I906, informa de la conferència sobre rondallística en què van participar Maria Baldó, Sara Llorens, Joana Vidal, Adelaida Ferrer i Rossend Serra Pagès. I, el mes següent, el 22 de desembre del 1906, publica el discurs «Notas sobre feminismo», de Maria Baldó.

I2. Al cap de pocs anys, el I909, ran d'una conferència impartida per Manuela Fina sobre llegendes fineses al Centre Excursionista, una nota de la revista Feminal que se'n fa ressò acaba amb el comentari que aquesta autora entra a formar part de l'estol de folkloristes, «petit però remarcable», format per Sara Llorens, Maria Baldó, Adelaida Ferrer, Maria Gràcia Bassa, Joana Vidal i Mercè Ventosa, les quals, «amb altres cantants i pianistes formen un dels pocs nuclis intel-lectuals de les dones catalanes» (Feminal número 3I, 28 de novembre del 1909).

I3. Aquest seria el cas de Sara Llorens, Adelaida Ferrer, Joana Vidal, les germanes Queraltó, Maria de la Gràcia Bassa, Maria Baldó, Narcisa Freixas, Maria Patxot, Manuela Fina i Mercè Ventosa (Llopart I982: 53 i Oriol 2010: IO).

I4. Per exemple, el professor fou testimoni dels casaments d'Adelaida Ferrer i Maria Baldó (les segones noces) o l'encarregat per la família de donar la notícia a Maria Gràcia Bassa de la mort d'un dels seus germans. La mare de Maria Baldó va delegar en el professor de posar nom a la seva segona filla, Núria. Rossend Serra Pagès també va escriure una semblança del tot laudatòria sobre la seva deixebla Adelaida Ferrer (Feminal número 39, 26 de juny del I9IO). 
lore» (26 de juny del I905). O Maria Oller, que li escriu que ha de demanar permís al pare per acceptar una proposta que li ha fet Serra Pagès (24 d'agost del I9II). En algunes de les cartes també s'hi percep un cert coqueteig amb algunes de les deixebles, però habitualment des d'un to, per les respostes, paternalista. ${ }^{\mathrm{I} 5}$

S'excusen quan no poden assistir a les classes, habitualment per motius familiars. I pel plural utilitzat, són noies que van acompanyades a escoltar les conferències al Centre Excursionista o altres indrets. ${ }^{16}$ Són senyoretes que recullen materials per a senyoretes. Sara Llorens, ja en la primera carta que envia des de Pineda al professor (i8 de juny del I904), li comenta que, de les 250 cançons que ha recollit, n'haurà d'eliminar unes quantes perquè són «xavacanes» $\mathrm{i}$ «de lo més maliciós i de poc gust», «escombraries de lo més popular». Joana Vidal, en la seva recerca d'estiueig per Cadaqués, en què ja ha apuntat moltes dites, li escriu escandalitzada que «la cosa més curiosa ha estat trobar pescadors», però que no saben «res de res» i que el problema és que les cançons que proporcionen «són incopiables per lo exageradament pujades de to». I es lamenta que els pescadors continuen cantant altres cançons mentre ella els pregunta «pel barco fantasma i les sirenes» (26 de juliol del 1907). D'aquí, seguint els valors socials del moment de com i què havia de fer una dona com cal, que el material recopilat per les folkloristes siguin rondalles, llegendes, oracions, jocs, endevinalles, supersticions i cançons, i s'obviïn o refusin altres gèneres.

Les deixebles de Serra Pagès procedien de cercles burgesos i benestants. Eren alumnes d'una escola de prestigi i formaven part d'unes classes socials i amb una posició determinada. Joana Vidal, filla d'un advocat que escrivia a La Publicitat, parlava anglès i francès i tocava el piano. Maria Oller Rabassa era filla de l'escriptor Narcís Oller; i Narcisa Freixas Cruells, filla també d'un escriptor, Pere Freixas, fou una compositora i pedagoga musical reconeguda, que va fundar, el I908, l'Escola Cultura Musical Popular, en què també s'ensenyaven danses populars i va publicar reculls de cançons infantils i cançons popular catalanes. Maria Baldó i Sara Llorens ja tenien el títol de mestra quan es van matricular a l'Escola d'Institutrius, com Adelaida Ferrer, també amb el títol de mestra i amb estudis ampliats a l'Escola Municipal de Música de Barcelona i a les Escoles Superiors d'Arts i Indústries i Belles Arts de Barcelona. Consol i Rosa Planas eren filles d'una família gironina constructora de turbines que s'havia enriquit amb la industrialització. O, un últim exemple, les germanes Teresa i Emília Torras se'n van a la Gran Bretanya tot un any a estudiar anglès — amb poc profit, segons les cartes.

Hi havia algunes excepcions. Algunes deixebles s'han de guanyar la vida, com és el cas de Josepa Brichs, mestra a l'Escola d'Institutrius. O Maria Baldó —incansable amb un treball continuat en el camp de la pedagogia, dirigint una escola a

I5. Rossend Serra Pagès estava casat amb Felipa Font de la Vall i de Llanza, de la família del ducat de Solferino, que va fugir de casa el I892, poc després del naixement de la filla d'ambdós, Doloretes. Va ser trobada morta el 1920 en una residència de Barcelona (Pujadas 2004a: 323).

I6. Així, per exemple, Maria Baldó, a causa de la indisposició de la mare, «no han pogut assistir a les vetllades del Centre Excursionista» (2 de gener del I906). Emília Estartús només li pot enviar un recull molt curt perquè no ha pogut treballar per culpa de la malaltia de la seva tia (5 de juny del I906). Rosa Planas no ha pogut llegir el llibre recomanat pel mestre, ja que ha tingut la mare malalta (I6 de setembre del I9Io). Joana Vidal li escriu per comentar-li que «no vam poder assistir» a la sessió del folklore del Centre Excursionista perquè «la mare s'ha apoderat de mi» i, com que no té cap germana, «em necessita» (I909-I9IO). 
més de fer-se càrrec del negoci d'apicultura familiar en quedar-se vídua del primer marit- i Adelaida Ferrer - mestra d'arts plàstiques i de brodats i puntes en diverses escoles, folklorista i historiadora de la punta catalana (Llodrà 2007). O el cas d'Antònia Quinquer, que manté una relació epistolar molt intensa entre els anys I909 i I9Io i secreta per als de casa seva —es fa enviar les cartes a l'adreça d'una altra deixebla, Maria Vidal- amb el professor sobre diverses qüestions de les quals no pot parlar a les classes. Antònia Quinquer, que recollirà i harmonitzarà cançons populars, planteja al mestre tot un seguit de dubtes sobre el seu futur, ja que la situació familiar l'obliga a estudiar «Teneduria» (títol que obtindrà el I9II) i fer-se càrrec dels comptes del negoci familiar i, així, li escriu sobre les professions adients per a les dones, els seus intents d'emprendre altres estudis o buscar feina, dels seus problemes de relació amb els homes i en contra del matrimoni o dels seus desigs de guanyar-se la vida de manera independent i «valdre's sola» (Bosch I997: II7-I34).

Aquesta posició acomodada, ja que eren alumnes que residien a Barcelona, la reblen les cartes datades des de diversos llocs on viatjaven o estiuejaven. Moltes de les cartes són enviades des de llocs d'estiueig. Emília Estartús Prats li comunica que, potser, a l'estiu tindrà l'ocasió de «trobar folklore francès» (26 de juny del I905). En la seva carta en castellà, Carmen Fernández li explica que «Salinas se va quedando sin veraneantes, baños de playa, clubs y bailes» (25 de setembre del I909). Consol Planas Regordosa passa una llarga temporada al Grand Hotel Cauterets, on té «molta feina» per divertir-se, per «aprendre a muntar» i fer excursions amb els oncles (I8 d'agost del I9I2). La també professora de l'Escola, Josepa Brichs Quintana, li fa arribar novetats d'altres condeixebles, com la Maria Genís, que ha estat a Friburg (I d'agost del I9I5), o les «senyoretes» Pascual, que estan tot el dia «fent equitació al picadero» (25 d'agost del I9I5). Les germanes Teresa i Emília Torras li envien cartes des l'estiueig a Calella de Palafrugell, on pinten «quadrets», surten a navegar o es banyen en cales particulars per a elles soles perquè ningú no les miri (4 de juny del I9I2). Les tres trameses de Mercè Torres, per exemple, corresponen a dues cartes des de Tiana (27 d'agost del I926 i 6 de setembre del I928), en què li explica els banys, les excursions amb vaixell i els desconsols que li provoquen les pèrdues del Barça, i una postal des de Berlín (29 d'agost del I927), on està de viatge amb el seu pare i la seva germana Magdalena, la qual li envia al seu torn una altra postal on li comunica que fa frescor i que estan tancats a l'hotel perquè hi ha calefacció (2I d'agost de I927). ${ }^{\text {I7 }}$

És a través dels viatges i les estades d'estiu que informen el mestre de les recerques que fan de materials de folklore i, també habitualment, els informants solen ser, a més de la gent de l'indret, les minyones, els mossos o els treballadors de la casa o del negoci familiar. Però sempre les recerques folklòriques queden en un segon terme $i$, en les seves existències, passa per davant la feina de cura, en cas d'haver d'atendre les malalties i necessitats del pare o la mare o altres familiars com a filles o, posteriorment, per complir les seves tasques d'esposes i mares. Seguint aquest patró, quan les deixebles de Rossend Serra Pagès es casen, ${ }^{18}$ canvien

I7. Sobre els costums de l'estiueig de la burgesia barcelonina, és curiosa una carta de Sara Llorens al professor (9 de juny del I9I7) en què li comenta que no li ha trobat cap casa per llogar per a l'estiu, perquè la «demanda es extraordinària» i augmenta d'any en any.

I8. Generalment amb membres de bones famílies de la burgesia i, curiosament, moltes ho fan amb metges (Mercè Ventosa, Rosa Planas, Joana Vidal, Narcisa Freixas i Maria Vivó). 
el to epistolar per un de més formal, passen a firmar amb el «de» i el cognom del marit $\mathrm{i},{ }^{19}$ en bona majoria, abandonen els estudis o les recerques. L'autoritat del pater familias també es fa evident en diferents cartes; així, quan el mestre proposa a Maria Baldó que faci una comunicació en un congrés de Lleida, ella no li pot respondre fins que ho consulti amb el seu marit, Josep Serra (I2 de juliol del I9II). ${ }^{20}$

La seva existència va lligada al matrimoni i a la vida dels seus esposos. Quan es casen, en general, les cartes es van esponjant o s'extingeixen, de la mateixa manera que va acabant en aquests casos les seves dedicacions a la recollida de material i al treball de camp. Rosa Pagès Bataller, per exemple, acompanyarà el seu promès a Suïssa perquè, encara que ell hi havia estat, «es va deixar de visitar una casa a Lucerna» (9 d'abril del I9IO), i la darrera carta, ja casada, li informa que, mentre passa l'estiu a la masia abans de tornar a Barcelona, ha trobat més de 300 goigs a la parròquia de Sant Joan de Valls (Io d'agost del I9IO). Un cas més significatiu és el d'Anna Queraltó Latorre, que, en les cartes que envia a Rossend Serra Pagès els primers temps, força seguides (9 cartes entre l'octubre del I9o9 i el 6 de juny del I9Io, des de Caldes de Montbui i Barcelona), li va anotant les seves activitats en la recollida d'oracions i cançons que harmonitza, li envia escrits perquè els corregeixi i acompanya al piano conferències al Centre Excursionista. Al mateix temps, inquieta i amb un joc de coqueteig amb el mestre, el qual li envia cartes

I9. Això fa que, en alguns casos, encara resti pendent esbrinar els dos cognoms d'algunes de les deixebles, tot i saber, però, en canvi, el nom dels seus marits. Tant una dada com l'altra ajuden a traçar noves pistes i nous camins per recompondre la seva història. Aquest seria el cas de Maria Vivó, casada amb el cirurgià Julio Nin Silva, amb qui va tenir quatre fills. D’Emília i Magdalena Torras només sabem que signaven com a Emília Torras de Plana i Teresa Torras de Llimona, sense cap més dada. Tampoc no tenim dades del segon cognom d'Antònia Orriols, Carmen Fernández, Mercè i Magdalena Torres, ni els dels seus marits en cas que es casessin. Tot indica que Maria Oller Rabassa i Antònia Quinquer Golobart no van contraure matrimoni. De la resta, sí que hi ha dades més o menys completes: Maria Gràcia Bassa es va casar amb Joan Llorens Carreras; Maria Baldó Massanet amb Josep Serra Chartó i, en quedar-se vídua, amb Lluís Torres Ullastre; Adelaida Ferrer Gomis amb Rafael Ruiz Nárvaez; Manuela Fina Vergés amb Jaume Sapera Ribot; Emília Estartús Prats amb Josep Marimon; Narcisa Freixas Cruells amb Josep M. Petit; Sara Llorens Carreras amb Manuel Serra Moret; Rosa Pagès Bataller amb Daniel Sagú Sanromà; Rosa Planas Regordosa amb Francesc Pons Pasqual; Consol Planas Regordosa amb Antonio Tortras Atmella (1922); Anna Queraltó Latorre amb Ramon Aragay Blanchart; Mercè Ventosa Roca amb Isidre Marca Ripoll, i Joana Vidal amb Joan de Déu Soler Badia. I cal afegir, sense altres dades, que Josepa Brichs Quintana signava, casada, com Josepa Brichs de Sabaté.

20. Manuela Fina Vergés i Jaume Sapera Ribot s'havien fet socis del Centre Excursionista el I906, any en què Rossend Serra Pagès també hi impartí un curs de folklore (Butlletí del Centre Excursionista de Catalunya volum I2, 1907). El 1909, Manuela Fina fou elegida vicesecretària de la Junta directiva de la Secció de Folklore del Centre i va impartir la conferència d'inauguració del curs. Aquesta conferència va ser reproduïda anys més tard per $\mathrm{La}$ Veu Comarcal de Ripoll (26 d'agost del I9I6) i, al cap de pocs dies (3I d'agost del I9I6), Jaume Sapera enviava una carta al seu director, Tomàs Raguer, en què prohibia publicar més articles de la seva esposa («Correspondència cultural dels Raguer», Arxiu Comarcal del Ripollès). Aquesta mateixa conferència es repetí a l'Ateneu Empordanès, però fou llegida pel seu oncle Eusebi Fina Girbau, president de l'entitat, i no pas per l'autora (Ofrena número 3, gener del I9I7). Posteriorment, el I938, el seu únic fill, Joan Antoni Sapera Fina, fou condemnat pel govern de la República a I5 anys per delictes d'espionatge i traïció i internat en un camp de treball a Omells de na Gaia i, ja en la dictadura, quan aquest va tenir càrrecs a la judicatura, la «senyora Fina de Sapera» sembla que es va moure en altres cercles socials, segons algunes mencions de la premsa. 
«plenes de lirisme i bon humor», li explica les seves dèries i les visites a les consultes d'«una sonàmbula que endevina i tira cartes» i a d'altres «tiradores» de cartes. La correspondència s'interromp, i, al cap d'un any, el «benvolgut i amic i mestre» esdevé «respectable i apreciat amic» i, lacònicament, li comunica que es casa (3 de desembre de I9II). Una última carta, en què tampoc ja no hi ha cap tema sobre folklore, li comenta que «encara no està acostumada a la nova vida», que està esperant una criatura i signa com a Agna Queraltó d'Aragay. En canvi, amb Maria Vivó, s'inicia la correspondència el I920, quan ella ja s'havia acabat d'instal-lar a Montevideo, casada amb el metge Julio Nin Silva, de procedència tarragonina per part de pare, que fou fundador de la Sociedad de Cirurgía del Uruguay i amb qui va tenir 4 fills. Maria Vivó — que manté també relació amb Maria Gràcia Bassa, Sara Llorens i Maria Baldó- agraeix al professor els llibres i revistes que li envia i, al mateix temps que li informa de les novetats familiars, expressa el seu desig del triomf del catalanisme (I924) o li explica que han rebut la visita «d'un català molt lluitador, Macià, i d'un jove que crec que és poeta, Gassol» (I4 de gener del I928). Més cauta és Maria Gràcia Bassa a qui també van visitar a casa seva a Buenos Aires (I2 de juny del I928) els mateixos personatges il-lustres, però que ella no anomena perquè «els consideraven fugitius».

Malgrat els paràmetres conservadors, moltes d'aquestes dones són dones actives i inquietes que no es resignen al paper domèstic. I amb opinions pròpies. Ja he esmentat les trajectòries musicals i pictòriques respectivament de Narcisa Freixas i Maria Oller i les pedagògiques de Maria Baldó i Adelaida Ferrer. He fet referència a les opinions pròpies d'emancipació d'Antònia Quinquer, en certa manera semblants a les que exposa en diverses cartes Mercè Ventosa, que es manifesta en contra de la família i el matrimoni i expressa els seus dubtes sobre la religió. Mercè Ventosa, a més de portar els llibres de comptabilitat de la fàbrica del seu pare i recopilar materials folklòrics, conreava la pintura. Maria Baldó i Sara Llorens, ja el I906, participaran en el primer Congrés de la Llengua Catalana. Sara Llorens, marcada per la malaltia, no cessarà en tota la seva existència d'escriure —creació literària i articles—, recopilar i publicar estudis i materials folklòrics i tindrà molt a veure en la creació de la Biblioteca de Pineda de Mar i en les activitats que s'hi organitzaven quan el seu marit, Manuel Serra Moret, en fou alcalde. Socialista, casada pel civil, Sara Llorens no creu en la religió i defensa el catalanisme contra la centralització. La seva cunyada, Maria Gràcia Bassa, escriu articles a la revista Ressorgiment de Buenos Aires i col-labora amb el Centre Català organitzant cursos i conferències. Sara Llorens explicava al mestre que «Gracieta segueix molt activa en qüestions de propaganda nacionalista i bastant en cultiu literari» (Buenos Aires, 8 d'octubre del I925). La política tampoc serà aliena per a Antònia Quinquer, membre de la secció femenina de «La nostra parla» i secretària de la «Junta auxiliadora de Dones de la Lliga del Bon mot», militant d'Acció Catalana i del Comitè Pacifista de Dones. O per a Maria Baldó, d’Esquerra Republicana. Ni el feminisme. Maria Gràcia Bassa i Maria Baldó publicaran conferències i articles sobre el paper de les dones i el feminisme (Palau 20I2: I3-25). Sara Llorens, en referència a un seu cunyat que està dilapidant «la seva hisenda a passos de gegant», es lamenta que la seva germana Orfèlia no pugui actuar, perquè la llei no ajuda «una dona de capacitat a prendre les regnes de la casa d'unes mans aixís!» (22 de desembre del I923). O, en un article, «La felicitat i la bellesa» (Feminal número 53, 27 d'agost 
del I9II: 2-3), tradueix un text de Stella Stuart per advocar per la instrucció i la «cultura femenina».

Eren dones instruïdes que, a més de parlar de folklore amb Rossend Serra Pagès, hi intercanviaven lectures i bibliografia, o opinions sobre filosofia, religió, política o la tasca que duia a terme Pompeu Fabra amb la llengua catalana. Al mateix temps, però, seguint els dictats de l'època sobre la feminitat, eren no escriptores o folkloristes, sinó dones que escrivien o estudiaven el folklore. Així, tot i la feina que van dur a terme, sempre, des de l'inici fins al final de la vida del seu professor, quan ja en les cartes es dirigien al «preuat» $\mathrm{o}$ «estimat amic», sempre van demanar-li consell amb la consideració que els seus treballs eren "poca cosa». Sara Llorens, en haver de classificar unes rondalles en uns moments en què no disposava de llibres ni de temps, es queixa del seu «cervell femení»: "A les dones dongui'ns treballs de recol·lecció, d'investigació, de documentació, treballs d'arxiu, de laboratori... però no treballs de síntesi» (28 de febrer del I9ı6). Amb termes semblants s'expressa Maria Gràcia Bassa: «el meu pobre cervell és massa poca cosa» (I de març del I905). També Adelaida Ferrer es vanta de la seva «pobre intel-ligència» (9 de juny del I905) i Anna Queraltó li demana que «endreci»els seus escrits (27 de juny del I9Io). Joana Vidal li comenta que no sap «on arribarà la meva poca intel-ligència i menys coneixements» i no es considera ni amb traça ni imaginació i espera que el mestre li digui si algun dels seus «papers embrutats» pot valdre (8 d'octubre del I905). Sempre van demanar el permís i les correccions del seu mestre. Un model que no s'apartava de la ideologia burgesa, sinó que seguia els seus cànons. El final d'un article a la revista Feminal, que informava de la trajectòria pictòrica i folklòrica de Mercè Ventosa, ho ben resumia: «sense sortir de la llar», aquestes dones «desempenyen la seva missió femenina noble i dignament» (número 34, 30 de gener del I9IO). El mateix Rossend Serra Pagès va expressar quins eren els paràmetres d'aquest model tot remarcant que no era pas poc pels temps que corrien que «una senyoreta estudiï aquestes coses» - a més del que ja han d'estudiar «per lluir-se tan sols»—, com la gramàtica, la literatura o el folklore, que són «un acte de raciocini» i «un enaltiment de l'esperit» però, això sí, sense caure «del cantó d'aquella pseudosaviesa que empalaga» (Soler Amigó 20Io: 36).

L'epistolari que algunes deixebles van mantenir amb el professor Rossend Serra Pagès aporta més claus per definir i descriure els canvis socials de les dones catalanes a principis de segle. Una modernització que incideix en la seva educació no solament com a mares, sinó també com a persones, en l'accés a la formació i al treball intel-lectual i remunerat, però sense qüestionar altres reivindicacions o els models vigents de mares i esposes, des de posicions conservadores. Tot i el perfil conservador, aquest feminisme de signe social i no polític va incidir, com ha analitzat Mary Nash, en la modernització i professionalització de les dones catalanes des de l'argumentació que «els valors femenins i l'experiència de les dones en el seu rol de mares i esposes els permet desenvolupar una tasca social i cultural àmplia en el si de la societat». I crear, al mateix temps, una ciutadania «diferenciada per gènere que es tradueix en una ciutadania social per a les dones» (I997: IO7-IO8). Algunes de les folkloristes catalanes d'aquesta època, deixebles de Rossend Serra Pagès, exemple d'aquest feminisme cultural, van evolucionar i, amb el temps i les circumstàncies històriques, a més de continuar les seves trajectòries professionals i intel-lectuals, foren defensores del dret al sufragi, partidàries dels valors republicans i, també, van haver de patir l'exili. 


\section{Referències bibliogràfiques}

Bosch, Anna (I997): «Antònia Quinquer. Una veu de dona des de la Barcelona de principi de segle». Duoda número I2: II7-I34.

CAPMANY, Maria Aurèlia (I973): El feminisme a Catalunya. Barcelona: Nova Terra.

CURBERT, Jordi (2007): «Madre, memorialista y lexicógrafa: una vida entre palabras, Irene Rocas (I86I-I947)». El Filandar-O Fiadeiro núm. I7: II-V.

GRAU, Dolors (I999a): Memòries d'Irene Rocas (I86I-I9Io). Palafrugell: Ajuntament de Palafrugell.

- (I999b): «De Llofriu a Buenos Aires. La presencia empordanesa a América». Revista de Girona núm. 192: 36-42.

JuAn Nebot, Maria Antònia (2OII): «Rossend Serra Pagès i la recerca científica del folklore a Catalunya: El cançoner tradicional català i el Cançoner del Ripollès». Annals del Centre d'Estudis Comarcals del Ripollès 2009-20IO: 55-76.

LlodrÀ Nogueras, Joan Miquel (2007): «Aurora Gutiérrez i Adelaida Ferré. L'art de la punta al coixí a l'entorn del modernisme». Real Acadèmia de Belles Arts de Sant Jordi. Butlletí XXI: 37-55.

LLOPART, Dolors; Roser Ros (2OI2): «Dona i folklore. Apunts per a l'estudi del folklore compilat per dones a cavall de finals del segle XIX i les primeries del segle XX». Dins Josep TemPoral; Laura Villalba (eds.): La recerca folklòrica: persones $i$ institucions. Alacant: Institut Alacantí de Cultura Juan Gil-Albert / Arxiu de Tradicions de l'Alguer, p. 43-54.

NASH, Mary (I997): «Dolors Monserdà i el feminisme de la seva època». Memorials ICD, I993-I996. 2 vols. Barcelona: Institut Català de la Dona, p. Io3-Io9.

Oriol, Carme (2OIO): «Introducció». Dins Joan SOlER I AMIGó: Joana Vidal, folklorista. Valls: Cossetània, p. 9-II.

- (20I2): «L'aportació de les dones folkloristes a la Revista Arxiu de Tradicions Populars». Dins Josep TEMPORAL; Laura VILLALBA (eds.): La recerca folklòrica: persones i institucions. Alacant: Institut Alacantí de Cultura Juan Gil-Albert / Arxiu de Tradicions de l'Alguer, p. 55-68.

PALAU, Montserrat (2OI2): «Les aportacions al feminisme de les folkloristes Maria Gràcia Bassa i Maria Baldó». Dins Josep Temporal; Laura VillalbA (eds.): La recerca folklòrica: persones i institucions. Alacant: Institut Alacantí de Cultura Juan Gil-Albert / Arxiu de Tradicions de l'Alguer, p. I3-25.

PUJADAS, Joan (2004a): Sara Llorens. Epistolari (I9OI-I954). Barcelona: Fundació Pere Coromines.

— (2004b): Àlbum Sara Llorens. Pineda de Mar: Ajuntament.

REAL, Neus. (2006): Dona i literatura a la Catalunya de preguerra. Barcelona: Publicacions de l'Abadia de Montserrat.

RoMA, Francesc (I998): «Dona i excursionisme. Una passejada per la literatura excursionista de muntanya.» <http://www.francescroma.net/web/genere.pdf> [Data de consulta: novembre 20I3]. 
ROMA, Josefina; Dolors MARÍN (I996): «Sara Llorens i el seu Rondallari. Una dona fent treball de camp a començaments de segle». Anuario de hojas de Warmi núm. 7: 79-88.

Roma, Josefina (2006): «Introducció». Dins Sara Llorens: Rondallari de Pineda. Pineda de Mar: Ajuntament, p. 29.

— (2OII): «Palmira Jaquetti y la investigación del folklore musical». Temas de Antropología Aragonesa núm. I8 (20IO-2OII): I95-2IO.

- (20I2): «Sara Llorens, una maestra de la investigación folklórica». Tantàgora núm. I4 (primavera): I6-23.

SANMARTí, Carme; Montserrat SANMARTí (2OIO): Catalanes del IX al XIX. Vic/Tarragona: Eumo / Publicacions URV.

SERrA I Boldú, Valeri (I935): «El folklorista Serra i Pagès». Catalunya social núm. 74I-743 (24 de desembre): 827-828.

SERRA PAGÈs, Rossend (I926): Alguns escrits del professor Rossend Serra y Pagès, coleccionats y publicats a honor del Mestre per les seves deixebles en ocasió del Cinquantenari del seu Professorat (I875-I925). Barcelona: Estampa de la Casa Miquel-Rius.

SOlER I AMIGó, Joan (20IO): Joana Vidal, folklorista. Valls: Cossetània.

VILLALBA, Laura (2OI2): «La dona catalana i els estudis folklòrics a principis del segle XX: recuperant les genealogies perdudes». Dins Josep TEMPORAL; Laura VillalbA (eds.): La recerca folklòrica: persones i institucions. Alacant: Institut Alacantí de Cultura Juan Gil-Albert / Arxiu de Tradicions de l'Alguer, p. 27-42.

- (20I3): «Les folkloristes a la premsa catalana del primer terç del segle Xx: un tabú en la història del folklore català» Dins Anna FRANCÉs; Jaume GUISCAFRÈ (eds.): Erotisme i tabús en l'etnopoètica. Alacant: Institut Alacantí de Cultura Juan Gil-Albert / Arxiu de Tradicions de l'Alguer, p. 99-I25.

\section{Arxius i revistes en línia}

Butlletí del Centre Excursionista de Catalunya (I89I-I938). Centre Excursionista de Catalunya. Barcelona: <http://ddd.uab.cat/record/276I3> [Data de consulta: novembre 20I3].

Correspondència CUltural Dels RAguer. Arxiu comarcal del Ripollès: <http://www.arxiucomarcalderipoll.org/pdf/acriraguero5.pdf > [Data de consulta: novembre 20I3].

Feminal (I907-I9I7). Ilustració Catalana. Barcelona <http://www.diba.es/xbcr/default.htm $>$ [Data de consulta: novembre 20I3].

Fons RosSEnd SERRA PAGÈs. Arxiu històric de la ciutat de Barcelona. Part I: < http:// wiro.bcn.cat/ArxiuHistoric/Continguts/Documents/Fitxers/Serra\%20 Pag\%C3\%A8s, \%20Rossend\%20\%28Ia\%2opart\%29\%20\%285D.6I\%29. pdf >; Part 2: <http://wiıo.bcn.cat/ArxiuHistoric/Continguts/Documents/ Fitxers/Serra\%2oPag\%C3\%A8s,\%2oRossend\%20\%282a\%2opart\%29\%20 \%285D.6I\%29.pdf> [Data de consulta: novembre 20I3].

Or i Grana. Setmanari Autonomista pera las Donas (I906-I907). Barcelona: <http:// www.diba.es/xbcr/default.htm $>$ [Data de consulta: novembre 20I3]. 
Annex $^{21}$

\begin{tabular}{|c|c|c|}
\hline NOM $^{22}$ & CORRESPONDĖNCIA & CARTES \\
\hline $\begin{array}{l}\text { Maria Gràcia Bassa (Llofriu I883 - } \\
\text { Buenos Aires I96I) }\end{array}$ & I9O5-I928 & I5 \\
\hline $\begin{array}{l}\text { Maria Baldó Massanet (Hellín I884 - } \\
\text { Tolosa del Llenguadoc I964) }\end{array}$ & I9O4-I926 & $4 \mathrm{I}$ \\
\hline Josepa Brichs Quintana & I9II-I9I5 & 6 \\
\hline Carmen Fernández & 1909 & I \\
\hline Adelaida Ferrer Gomis (Barcelona I88I-I955) & I9O4-I927 & $3 \mathrm{I}$ \\
\hline Manuela Fina Vergés († Barcelona I965) & I9IO-I9II & 3 \\
\hline $\begin{array}{l}\text { Narcisa Freixas Cruells (Sabadell I859- } \\
\text { Barcelona I926) }\end{array}$ & I9I4-I9I5 & 4 \\
\hline Emília Estartús Prats († Barcelona I928) & I905-I906 & 2 \\
\hline $\begin{array}{l}\text { Sara Llorens Carreras (Lobos, Argentina I88I } \\
\quad \text { - Perpinyà I954) }\end{array}$ & I9O4-I929 & I 27 \\
\hline Maria Oller Rabassa (Barcelona I875) & I9II-I926 & 7 \\
\hline Antònia Orriols & I9IO-I9II & 4 \\
\hline Rosa Pagès Bataller & I908-I9IO & 3 \\
\hline Rosa Planas Regordosa († Barcelona I968) & I9IO-I9I2 & 6 \\
\hline Consol Planas Regordosa († Barcelona I970) & I9II-I9I2 & 3 \\
\hline Anna Queraltó Latorre ${ }^{23}$ & I909-I9I2 & IO \\
\hline Antònia Quinquer Golobart & I909-I92I & I4 \\
\hline Teresa i Emília Torras & I920-I922 & 9 \\
\hline Mercè Torres & I926-I928 & 3 \\
\hline Magdalena Torres & I927-I928 & 3 \\
\hline Mercè Ventosa Roca & I9O8-I925 & $\mathrm{I} 2$ \\
\hline Joana Vidal Tarragó (Barcelona I882-I957) & I9O4-I927 & 2I \\
\hline Maria Vivó († Montevideo) & I920-I929 & II \\
\hline
\end{tabular}

2I. L'epistolari consultat es troba en el ja esmentat fons Rossend Serra Pagès de l'Arxiu Històric de Barcelona. La correspondència de Sara Llorens també es recull en el llibre de Pujadas (2004a) i la de Joana Vidal en el de Soler Amigó (2010).

22. Com ja he esmentat, manquen encara dades biogràfiques sobre algunes de les deixebles. He partit del quadre més actualitzat (Villalba 20I2: 38-4I), tot aportant noves dades com és el cas del segon cognom de Josepa Brichs, Emília Estartús i Antònia Quinquer. També he intentat de fixar, en alguns casos sense èxit, les dates de naixement i mort de les diferents deixebles.

23. Sí que he trobat, en canvi, les dades de la germana, que també va assistir a l'Escola i a les classes del mestre, Antònia Queraltó Latorre (Barcelona I885 - Granollers I964). 